IOSR Journal of Pharmacy

ISSN: 2250-3013, www.iosrphr.org

Volume 2 Issue 5 \|ा| Sep-Oct. 2012 |ㅔ PP.15-26

\title{
A comprehensive review of diagnostic techniques for detection of cryptosporidium parvum in stool samples
}

\author{
Prakriti Vohra* ${ }^{1}$, Madhu Sharma ${ }^{2}$, Uma Chaudhary ${ }^{3}$ \\ ${ }^{I}$ (Demonstrator, deptt. of microbiology, PGIMS, Rohtak, \\ ${ }^{2}$ (Professor, deptt. of microbiology, PGIMS, Rohtak, \\ ${ }^{3}$ (Professor, deptt. of microbiology, PGIMS, Rohtak
}

\begin{abstract}
Cryptosporidium parvum is a significant cause of gastrointestinal disease in humans. Many diagnostic techniques are available for its detection. Most of these include-Microscopic methods, Serological methods, and Molecular methods. The present review aims in describing various diagnostic techniques available along with their advantages and limitations.
\end{abstract}

Keywords-Cryptosporidium parvum, diagnostic techniques, stool sample

\section{INTRODUCTION}

Cryptosporidiosis is caused by protozoan parasites of the genus Cryptosporidium (family Cryptosporidiidae, order Eucoccidiorida, subclass Coccidiasina, class Sporozoasida, phylum Apicomplexa).[1] Cryptosporidium parvum is the most common species in humans leading to life-threatening chronic diarrhoea in immunocompromised individuals.[2] C. felis, C. muris, and C. meleagridis have also been identified in immunocompromised persons.[3,4,5].

\subsection{Epidemiology}

The global prevalence of this parasite can be ascertained by the reports from all continents.[6] Epidemiologic studies have demonstrated that Cryptosporidium is more prevalent in developing countries (5\% to $10 \%$ ) than in developed countries $(1 \%$ to $3 \%)$. $[7,8,9,10]$ In Asia, the organism has been detected in $2-20 \%$ of all the cases of acute diarrhea.[11],[12] In India, the few reports that are available indicate a prevalence rate between 4 and 13\%.[13,14,15,16] Reports from West Mumbai[16] and Bengal [17] showed the parasite to be prevalent in $4.45 \%$ and $5.5 \%$ of children with diarrhea respectively, whereas a lower prevalence rate of $1.3 \%$ was reported from North India.[18] However, the detection of cryptosporidium in India is limited to major research laboratories and does not feature in protocols for routine investigations in most clinical laboratories.

\subsection{History, General Characteristics \& Transmission}

First reported description of C.parvum was in 1907 in gastric crypts of laboratory mouse (Tyzzer). Subsequently, it has been found in chicken, turkeys, mice, rats, guinea pigs, horses, pigs, calves, sheep, rhesus monkeys, dogs, cats and humans.

Cryptosporidiosis is a zoonosis and is transmitted by faecal-oral route. This infection is now well recognized as causing disease in humans, particularly those who are in some way immunosuppressed or immunodeficient. Calves and other animals perhaps serve as potential sources of human infections.[19]

\subsection{Clinical Manifestations}

\subsubsection{Intestinal}

C.parvum in an immunocompetent host causes a self-limiting infection, with diarrhoea and abdominal pain lasting 1-2 weeks. However, in AIDS patients, it causes profuse and watery diarrhea. It may produce fluid loss of over 10L/day.[20]

\subsubsection{Extraintestinal}

Cryptosporidiosis is not always confined to gastrointestinal tract. Additional symptoms (respiratory cryptosporidiosis, cholecystitis, hepatitis and pancreatitis) have been associated with extra-intestinal infections.[20]

Extra intestinal cryptosporidiosis has been reported principally in patients with AIDS. It may involve the lungs, middle ear, biliary tract, pancreas, and stomach. These sites probably represent extensions of a primary intestinal infection. Biliary cryptosporidiosis is the most common extraintestinal manifestation of infection. It was described in up to 26 percent of patients with AIDS and intestinal cryptosporidial infection in the era before highly active antiretroviral therapy. The true frequency of this entity is difficult to determine, 
because invasive procedures are required for diagnosis. The clinical features include pain in the right upper quadrant, nausea, vomiting, and fever, usually accompanied by elevated serum alkaline phosphatase levels. Those with biliary symptoms have lower CD4+ T-cell counts. A biliary reservoir of cryptosporidium may contribute to the chronic nature of the infection and the inability of therapy to eradicate the organism. Although biliary cryptosporidiosis increases morbidity in patients with AIDS, it may not affect survival. Respiratory involvement is rare and is characterized by cough, dyspnea, fever, and thoracic pain.[21]

\section{PATHOGENESIS}

Histological changes associated with intestinal cryptosporidiosis are relatively non-specific and include blunting of villi, hyperplasia of intestinal crypt cells, and infiltration of inflammatory cells into the luminal propria. Neutrophilic infiltrate, villus blunting, cryptitis, epithelial apoptosis and reactive epi thelial changes in the intestine in AIDS patients with cryptosporidiosis correlate with the intensity of $C$. parvum infection. Biliary cryptosporidiosis is also associated with a nonspecific inflammatory response. Histologically, there is a periductal inflammatory response with interstitial edema, mixed inflammatory cell infiltrates, and hyperplasia and dilatation of the periductual glands. The fibrosis that develops around the portal tracts of AIDS patients with chronic cryptosporidial infection can mimic the histologic changes seen in primary sclerosing cholangitis. Autopsy reports and prospective studies have supported an etiologic role for the organism in biliary syndromes like sclerosing cholangitis and acalculous cholecystitis. However, the pathophysiological mechanisms underlying $C$. parvum infection of intestinal and biliary epithelia are not well understood, and at present our understanding of the pathogenesis is still limited to data from animal experimental studies.[22]

The pathogenesis of pulmonary cryptosporidiosis has yet to be fully clarified. The possibility that pulmonary involvement is due to inhalation of oocysts during an episode of vomiting or results from hematogenous dissemination has been a point of discussion. Although Cryptosporidium oocysts do not usually invade the intestinal mucosa, they have been found within macrophages, leading to reduced phagocytic ability. In addition, this parasite can multiply in macrophages in vitro, which suggests that extraintestinal parasites spread via circulating phagocytes. This hypothesis is supported by the presence of Cryptosporidium spp. within the blood vessels in the intestinal and pulmonary submucosa, as revealed by autopsy studies.[23]

Samples- Faeces is the specimen of choice. Other samples include- Sputum, Bronchial washings and duodenal or jejunal aspirations.[24]

III. DIAGNOSTIC TECHNIQUES FOR CRYPTOSPORIDIUM PARVUM List of various diagnostic techniques for detection of Cryptosporidium oocysts

\begin{tabular}{|c|c|c|}
\hline Srne. & TYPES OF TECHNIQUES & DETAILS \\
\hline 1. & $\begin{array}{l}\text { MICROSCOPIC } \\
\text { TECHNIQUES }\end{array}$ & $\begin{array}{ll}\text { 1) } & \text { Concentration techniques- } \\
\text { a) } & \text { Floatation methods- } \\
\text { - } & \text { Sheather's sugar solution } \\
\text { - } & \text { Zinc sulfate } \\
\text { - Saturated Salt solution } \\
\text { b) } & \text { Sedimentation methods } \\
\text { - } & \text { Formalin ether } \\
\text { - } & \text { Formalin ethyl- acetate } \\
\text { ii) } & \text { Iodine-Saline Wet mount } \\
\text { iii) } & \text { Staining methods- } \\
\text { a) } & \text { H\&E staining, } \\
\text { b) } & \text { Romanowsk区 stains } \\
\text { c) } & \text { Modified Acid-fast staining } \\
\text { d) } & \text { Safranine-methvlene blue staining } \\
\text { e) } & \text { Negative staining } \\
\text { f) } & \text { DMSO modified acid-fast staining }\end{array}$ \\
\hline 2. & $\begin{array}{l}\text { SEROLOGICAL } \\
\text { TECHNIQUES }\end{array}$ & $\begin{array}{l}\text { 1) Antigen detection methods } \\
\text { - Inmunochromatographic dipstick tests } \\
\text { (ICT) } \\
\text { - } \quad \text { Rnzyme Immunoassays (EIAs) } \\
\text { - Reverse Passive Heamaglutination } \\
\text { technique (RPHA) } \\
\text { ii) Antibody detection }\end{array}$ \\
\hline 3. & FLOW CYTOMETERY & \\
\hline 4. & $\begin{array}{l}\text { MOLECULAR } \\
\text { TECHNIQUES }\end{array}$ & $\begin{array}{l}\text { i) PCR,Real-time PCR, Multiplex PCR, } \\
\text { Nested PCR } \\
\text { ii) FISH } \\
\text { iii) LAMP }\end{array}$ \\
\hline
\end{tabular}




\section{a.}

\section{Microscopic techniques}

(i) Concentration methods

Stool concentration techniques include [1]-

a) Flotation methods - flotation of oocysts in Sheather's sugar solution, in zinc sulfate (1.18 or 1.20 specific gravity), or in saturated sodium chloride (1.27 specific gravity).

b) Sedimentation methods- Stool concentration techniques using sedimentation include formalin-ether and formalin-ethyl acetate.

Some workers have found no differences among these methods, whereas others have found the formalin-ether and sodium chloride flotations to be the most sensitive.[25,26,27,28] According to some researchers, the Sheather's sugar solution gives results equal to or better than those obtained with formalin-ether or formalin-ethyl acetate.[29,30,31]

When Sheather's sugar solution is used, oocysts appear pink-tinged by bright-field microscopy and bright and birefringent when viewed by phase-contrast microscopy. When left in Sheather's solution for $>15$ min, oocysts begin to collapse and lose their spherical shape. If one is looking for C. parvum oocysts in stool or other body fluid samples, it is advisable to centrifuge at $>500 \mathrm{x} g$ for at least $10 \mathrm{~min}$.[6]

As the Formalin-ethyl acetate sedimentation concentration procedure is already performed routinely in most clinical microbiology laboratories, preparation of the acidfast smear for detecting Crvptosporidium $\mathrm{sp}$. in the same sediment may reduce cost and technical time. The acid-fast smear provides a permanent record of the results, but the preparation and reading of the smear require some technical expertise. Sheather sucrose flotation concentration is easy to perform, and the pink, refractile oocysts are easily recognized under high power magnification, but the wet mounts should be examined within 15 min after preparation or the oocysts may collapse. This difficulty may prevent batching specimens if this method is used for a large number of stools.[29]

\section{Advantages}

\section{Limitations}

i. $\quad$ Iodine-saline wet mount [20]

Recommended as a routine screening procedure.

Limitations

Not a permanent record

ii. Staining techniques

Several widely used techniques for demonstrating Cryptosporidium oocysts in fecal specimens from humans and other animals are

\section{Hematoxylin \& eosin staining}

Developmental stage of the parasite appear as small, spherical, basophilic bodies ( 2 to 5 p.m depending on stage of life cycle) within the microvillous region of the intestinal mucosa. Transmission electron microscopy can be used to confirm diagnosis and reveals distinct life cycle forms, each within a parasitophorous vacuole confined to the microvillous region of the host cell. The location of these parasites has been described as intracellular-extracytoplasmic:intracellular because they reside within a parasitophorous vacuole, extracytoplasmic because they are confined to the microvillous region of the host cell.[32,33]

\subsubsection{Romanowsky stains}

Cryptosporidium oocysts stain blue to azure, often with a crescentic pattern; about four to six red Or purple dots may be seen, and there may be a clear halo surrounding the oocyst resulting from shrinkage.[27]

2.1.3.3. Modified Acid-fast staining

Cryptosporidium oocysts will appear as pink stained, round to oval structures of about 3 to $6 \mu \mathrm{m}$ in diameter, containing distinct internal structures.[34] Acid-fast stains can also be performed by using either the hot staining method. ${ }^{28}$ or the cold method.[35,36]

Cryptosporidium oocysts are acid-fast and readily identified microscopically with oil immersion at a magnification of X40. With the modified cold Kinyoun stain they stand out as dark red bodies 3 to $5 \mu \mathrm{m}$ in diameter against a green or blue background, depending on the counterstain.[37]

Advantages

Low cost, good for screening large number of samples [38], permanent stain, making it possible to send doubtful or scanty positive slides to a reference laboratory for confirmation.[34] Limitations

Low sensitivity; Low specificity, time-consuming procedure (about 30 to 45 minutes), requires intensive training and experience to interpret the results. [22,23,24,25] A common problem is distinguishing Cryptosporidium oocysts from other elements, such as moulds and yeast. [39,40]

The modified Ziehl-Neelsen staining is a low cost technique (about 0,15 US\$ per sample), while the cost for PCR-based diagnosis is considerably higher (about 7,60 US\$ per sample).[41]

2.1.3.4. Safranin- Methylene blue staining 
Cryptosporidium oocysts are seen as vivid orange-pink bodies approximately $5 \mu \mathrm{m}$ diameter., usually spherical or slightly ovoid. The sporozoites within the oocyst stain slightly darker and are sometimes arranged around the periphery.

\section{Advantages}

The method is rapid and simple. It can differentiate yeasts from oocysts.[42]

Limitations

Necessity for acid-methanol treatment before and vigorous heating during the safranin stage. Some old safranin powders may give unsatisfactory results but the liquid concentrates produced by Paramount Reagents have performed consistently well.

\subsubsection{Negative staining $[43,44]$}

The negative staining technique of Heine can be the first choice for screening of slides for Cryptosporidium spp. Doubtful or equivocally positive samples can be confirmed, using the modified ZiehlNeelsen staining or other, more sophisticated techniques.[34]

For the negative staining technique of Heine, a small amount of faecal matter is mixed with an equal amount of undiluted carbol-fuchsine solution on a microscope slide. A thin smear is prepared, allowed to air dry and examined using x10 eyepieces and an oil-immersion objective of x50 or x100 magnification. Cryptosporidium oocysts appear as unstained, strongly refractive, round to oval structures of about 3 to $6 \mu \mathrm{m}$ in diameter. Internal structures are slightly visible as darker specks inside the oocyst.[45]

Negative staining can be done with the help of- Carbolfuchsin, Safranin, 2-5\% light green and Malachite green. Negative staining techniques using nigrosin (Pohjola, 1984), light green, (Chichino et al., 1991), which stain background yeasts and bacteria but not the oocysts, have also been developed. Negative staining methods are faster but are considered by some to be less sensitive than conventional staining techniques (Casemore et al., 1985; Garcia et al., 1983). Effective diagnosis of cryptosporidial infections requires diagnostic tools to be fast, cost-effective, accurate, and sensitive. Counterstaining methods using carbol fuchsin and safranin are time-consuming, frequently stain for yeasts, and lack sensitivity (Baxby et al., 1984; Moodley et al., 1991; Smith et al., 1989). Immunological methods are expensive and can crossreact with other organisms (Clancy et al., 1994). Microscopy provides the advantage of direct visual confirmation of the presence of Cryptosporidium oocysts. The malachite green method is a practical, safe, and sensitive method of detecting Cryptosporidium oocysts in stool specimens than other staining methods. When the light green stain was used, the yeasts did not always take up the stain, greatly confusing diagnoses. Similarly, negative staining with nigrosin also results in yeasts remaining unstained (Pohjola, 1984). With the malachite green stain, yeasts were clearly differentiated from oocysts as they took up the stain. Because of the ease with which oocysts can be differentiated from yeasts, less experienced microscopists can still accurately diagnose cryptosporidial infections.[46]

Advantages

Compared to the modified Ziehl-Neelsen staining, it is simpler, cheap, (as it uses only one stain), needs less time for staining. The sensitivity of this technique can be increased by using phase-contrast microscopy or examination at $\mathrm{x} 400$ magnification.

\section{Limitations} illumination.

The lack of familiarity, phase-contrast microscope is needed, inferior results are caused by Köhler-

\subsubsection{DMSO Modified Acid fast staining [47]}

Although the above mentioned procedures are useful in the research laboratory, acid-fast staining is usually the method of choice for the clinical microbiology laboratory. Some modifications have incorporated dimethyl sulfoxide. $[47,48,49]$ This procedure yielded oocysts that were brilliant pink to fuchsia against a pale green background. Organisms seen on low-power screening were checked under oil immersion at x 100 for the Cryptosporidium-typical internal vacuole and material clumped to one side of the 4- to 5-,um cyst. In contrast to the results of conventional acid-fast stains, the internal morphology of the resulting material in this study was well preserved.

\section{Advantages}

It simplifies diagnosis and hastens initiation of supportive therapy, reduces the health risks inherent in prolonged handling of contaminated material.

\section{Limitations}

In any of the acid-fast methods, there may be some variability in stain uptake, related to the stain itself or the age of the oocysts after prolonged storage.[26,27,42,50]

\subsubsection{Fluorescent stains}

i) auramine-rhodamine [26,51]

Cryptosporidium oocysts give Yellow fluorescence [52]

ii) Auramine- phenol 
Cryptosporidium oocysts appear ring shaped (4-6 $\mu \mathrm{m}$ in diameter) and exhibit a bright yellow fluorescence.[52] iii) auramine-carbolfuchsin [53,54]

Cryptosporidia appear as very characteristic brightly fluorescent discs against a dark red background.[27]

iv) acridine orange [26,36].

\section{Advantages}

Rapid screening, higher detection efficacy than microscopy and ELISA [52]

Limitations

Low sensitivity; Low specificity and high cost (equipment), Considerable experience required to obtain an accurate diagnosis.

However, confirmatory staining of suspected oocysts by another method may be required.[26]

This approach may provide the most sensitive method available for the diagnosis of cryptosporidiosis. [55]

2.1.3.8. DFA Merifluor Cryptosporidia/Giardia kit (Meridian Diagnostics Inc., Cincinnati, Ohio) [56,57]

Cryptosporidium oocysts are seen as round to slightly oval shaped structures, 2-6 $\mu \mathrm{m}$ in diameter and Giardia cysts are oval-shaped, 8-12 $\mu \mathrm{m}$ long. Both of these give bright apple green fluorescence with DFA staining.

Advantages

Excellent specificity, improved sensitivity, Less skill recquired, takes less time. Additionally, the high quality of the reagents results in minimal background autofluorescence or nonspecific staining and enhances the identification of any organisms present.

Limitations

\subsubsection{Antibody Detection Methods}

\section{SEROLOGICAL TECHNIQUES}

The use of serodiagnostic techniques to monitor exposure to Cryptosporidium sp. has been limited to a few laboratories. Antibodies specific to Cryptosporidium sp. have been detected by an IFA procedure in sera obtained from persons who recovered from confirmed infections.[58,59] Specific anti-Cryptosporidium IgG, $\operatorname{IgM}$, or both were also detected, by an enzyme-linked immunosorbent assay (ELISA), in the sera of $95 \%$ of patients with cryptosporidiosis at the time of medical presentation and in $100 \%$ within 2 weeks of presentation.[60] According to one serologic survey, $>50 \%$ of persons with no known infection may have antiCryptosporidium IgG, suggesting recent exposure to the parasite.[61]

The limited seroprevalence data now available suggest that Cryptosporidium infections, many perhaps asymptomatic, are more common than the infection rates reported in surveys based on detection of fecal oocysts. Additional evaluations are needed to determine whether there is any correlation between the presence of Cryptosporidium-specific serum antibodies and resistance to reinfection and to confirm the utility of these serologic procedures for diagnosing and monitoring infections.

\subsubsection{Antigen Detection Tests}

3.2.1.1. Immunochromatographic dipstick tests (ICT):

I) Rida Quick Cryptosporidium

II) Cryptosporidium-Strip (Coris BioConcepts, Gembloux, Belgium). Advantages

\section{Limitations}

Sensitive, cost-effective methods

Not reliable as routine methods.

\subsubsection{Enzyme immunoassays (EIAs):}

I) Ridascreen Cryptosporidium (R-Biopharm).

Compared with the EIA tests, the dipstick kits had the advantage of being less time-consuming and simpler to carry out, and did not require an ELISA microplate reader or other specialised equipment. Microscopy can be false-negative for cases with a low parasite density, or when intact microorganisms are absent. Another important factor influencing the performance of copro-antigen assays is the study population. False-negative copro-antigen test results have been associated with low parasite densities.[62]

II) ProSpect Cryptosporidium microtiter assay (Alexon, Inc., Mountain View, Calif.)[63]

III) Color Vue Cryptosporidium assay (Seradyn, Indianapolis, Ind.)[63]

The Color Vue assay was judged to be slightly better suited for batch testing because it did not require a predilution step. A predilution step is required in the ProSpect assay. These pretesting processes add to the complexity of these methods and the time required to perform the tests.

Advantages

Less detection time, economical, lesser skill recquired. This ELISA will be particularly useful in laboratories not accustomed to diagnosing cryptosporidiosis often, in epidemiologic studies in need of diagnostic standardization, and in situations when batch specimen processing may be crucial.[64] Limitations 
Cost factor, False- positive results are common.

1) This may be soluble antigen(s) or other stages in the life cycle of Cryptosporidium, or merely a nonspecific background effect.

2) Rheumatoid factor, which may be present in body fluids during inflammation is a common cause of false positive EIA

Although potentially useful as a screening test, further development and refinement of the method is required before it could replace microscopy in the diagnosis of cryptosporidiosis.[65]

2.2.4. Reverse passive haemagglutination (RPH) technique [66]

Through sensitization of sheep erythrocytes with a Cryptosporidium anti-oocyst monoclonal antibody, Farrington et al.[67] have standardized a simplified laboratory technique to diagnose human infections with Cryptosporidium species.

Advantages

This technique is ideal for specimens that have been stored or delayed in transit.

Limitations

False-positive results.

List of commercially available assays for Cryptosporidium antigen detection in stool samples [68]

\begin{tabular}{|c|c|c|c|}
\hline Organism & Kit name & $\begin{array}{l}\text { Manufacturer - } \\
\text { distributor }^{\mathrm{a}}\end{array}$ & $\begin{array}{l}\text { Type of } \\
\text { Test }^{\mathrm{b}}\end{array}$ \\
\hline \multirow[t]{8}{*}{ Cryptosporidiumspp. } & Crypto CELISA & Cellabs & EIA \\
\hline & $\begin{array}{l}\text { PARA-TECT TMCryptosporidium } \\
\text { Antigen } 96\end{array}$ & $\begin{array}{l}\text { Medical Chemical } \\
\text { Corporation }\end{array}$ & EIA \\
\hline & ProSpecT Rapid & Remel & EIA \\
\hline & ProSpecT & Remel & EIA \\
\hline & Cryptosporidium & TechLab & EIA \\
\hline & Cryptosporidium & Wampole & EIA \\
\hline & Crypto CEL & Cellabs & IFA \\
\hline & XPect Crypto & Remel & Rapid \\
\hline \multirow[t]{7}{*}{$\begin{array}{l}\text { Cryptosporidiumspp./Giardia } \\
\text { lamblia }\end{array}$} & $\begin{array}{l}\text { PARA- } \\
\text { TECT }{ }^{\text {TM }} \text { Cryptosporidium/Giardia } \\
\text { DFA } 75\end{array}$ & $\begin{array}{l}\text { Medical Chemical } \\
\text { Corporation }\end{array}$ & DFA \\
\hline & Merifluor & Meridian & DFA \\
\hline & ProSpecT & Remel & EIA \\
\hline & Crypto/Giardia CEL & Cellabs & IFA \\
\hline & ColorPAC* & Becton Dickinson & Rapid \\
\hline & ImmunoCard STAT!* & Meridian & Rapid \\
\hline & XPect & Remel & Rapid \\
\hline
\end{tabular}

a Antibodies,Inc., P O Box 1560, Davis, CA 95617-1560

Becton Dickinson, 1 Becton Dr., Franklin Lakes, NJ 07417

BioSite, 11030 Roselle St., San Diego, CA 92121

Cellabs, P O Box 421, Brookvale, NSW 2100, Australia

Genzyme Virotech, Gmbh, Lowenplatz 5, 66248, Russelheim, Germany

Medical Chemical Corporation, 19430 Van Ness Avenue, Torrance, CA 90501

Meridian Bioscience, Inc., 3471 River Hills Dr., Cincinnati, OH 45244

Novocastra, 30 Ingold Rd., Burlingame, CA 94010

Remel, 12076 Santa Fe Drive, Lenexa, KS 66215

TechLab, VPI Research Park, 1861 Pratt Dr., Blacksburg, VA 24060

Wampole Laboratories, P O Box 1001, Cranbury, NJ 08512 
${ }^{\mathrm{b}}$ EIA = enzyme immunoassay; Rapid = immunochromatographic cartridge; DFA = direct immunofluorescence assay; IFA = indirect immunofluorescence assay.

2.3. Flow cytometery

Cryptosporidium oocysts, as discrete particles, can be detected by flow cytometry (FC) if labeled with an appropriate fluorescent tag. Arrowood et al.[69] described the use of this method, which employed a monoclonal antibody for evaluation of experimental cryptosporidial parasite loads in infected mice with severe combined immunodeficiency (SCID). Oocysts can be fluorescently labeled and counted by FC and Valdez et al [70] modified and extended the method of Arrowood et al [69] to human stool samples.

Luminex technology is a bead-based flow-cytometric assay that allows the detection of various targets simultaneously.[71] The microsphere beads can be covalently bound to antigens, antibodies, or oligonucleotides that will serve as probes in the assay. Up to 100 microspheres are available each emitting unique fluorescent signals when excited by laser therefore allowing the identification of different targets. Adapted to the study of parasites, the Luminex assay could identify multiple organisms or different genotypes of one particular organism during the same reaction utilizing very low volume. The approach could prove useful in the study of antigenic diversity and drug-resistance alleles and for the diagnosis of parasitic diseases. Luminex was applied to the study of Cryptosporidium. $C$. hominis and $C$. parvum cannot be distinguished using antigen detection or serology assays. Only DNA-based approaches have been successful in doing so by exploiting the single nucleotide difference in the microsatellite-2 region (ML-2) of both species.

Advantages

Simple and efficient method of processing human feces, more sensitive (approx.10 to 15 times) than conventional DFA.

Limitations

Need of an expensive setup \& technical expertise.[72]

\subsection{Molecular methods}

\subsubsection{Polymerase Chain Reaction (PCR)}

Due to its extreme sensitivity and specificity, the PCR-based detection of microbes in clinical samples is an attractive option. Fricker C.R. et al [73], Widmer G.et al [74], Morgan U.M.et al [75] have reviewed various methods for PCR-based detection of Cryptosporidium in clinical samples and drinking water. Some investigators have found high sensitivity for PCR-based assays (one oocyst) and suggest that these assays are more sensitive than microscopic analysis of acid-fast smears; unfortunately, no large comparative study has been performed to determine the ideal primers, PCR conditions, or stool extraction methods to use with clinical samples. Several factors complicate the PCR-based detection of C. parvum in stool. Standard fixation in $10 \%$ buffered formalin may reduce the sensitivity of the PCR, particularly if fixation occurs over an extended period. Also, extended formalin fixation may alter the buoyancy of $C$. parvum oocysts, interfering with standard methods for purification of $C$. parvum oocysts from stool. PCR detection of oocysts from frozen stool is also possible, but the sensitivity may be reduced, probably due to rupture of oocysts during thawing. One method for oocyst purification from stool commonly used in the research laboratory involves density gradient centrifugation of stool While this method provides purified oocysts, ideal for PCR analysis, it is more suitable for a research laboratory than a clinical laboratory and may not be useful for specimens containing few oocysts. The PCR can be inhibited by numerous substances, including some stool components. Several investigators have developed nucleic acid extraction methods for stool to remove these inhibitors. Unfortunately, many of these methods are quite complex, and detailed comparative studies have not been performed to identify the most useful technique.[76]

PCR is particularly amenable to automation and large throughput processing, and with bulk buying of reagents and modifications to the technique to reduce hands-on time, such as the use of 96-well plates for PCR setup and amplification, this cost could easily be further substantially reduced, thereby making PCR a more attractive option financially. However, a nonhomologous internal control could easily be constructed with commercially available kits such as the PCR mimic construction kit (Clontech, Palo Alto, Calif.), which would result in the amplification of a different-sized band with the Cryptosporidium diagnostic primers. This internal control could then be used to monitor the success of each PCR and would reduce the assay to a one-tube test, thus rendering it more cost-effective. For clinical as well as environmental laboratories, both the ability to detect pathogens reliably and the ability to determine the numbers of pathogens present are important. Quantitative PCR techniques such as the Taqman LS-50B PCR detection system (Perkin-Elmer, Foster City, Calif.) have recently been launched, and the test described in the present study could be eveloped into a quantitative PCR test with this technology; however, the cost of the assay would be significantly higher.[77]

Advantages

Sensitive technique; permits genotyping

Limitations

Nonstandardized methods; high cost; specialized training and equipment required 


\subsubsection{Real-Time PCR}

Real-time PCRs for detection of Cryptosporidium spp. and genotypes in human clinical samples have been described by Amar et al [78], Limor et al [79], Tanriverdi et al [80], Higgins et al [81]. However, none identify C. hominis and C. parvum and detect other Cryptosporidium spp. by amplifying a region which can be directly sequenced to identify species/genotype. Hadfield et al [82] described the development, evaluation, and clinical validation of a real-time PCR targeting $C$. hominis and $C$. parvum alleles of a locus of unknown function, LIB13, while simultaneously detecting all known Cryptosporidium species and genotypes by amplification of a region of the SSU rRNA gene allowing identification by direct sequence analysis. The assay also incorporates an exogenous internal control (IC) for the identification of inhibited reactions.

Tnrivedri et al [83] reported the development of real-time PCR assays capable of detecting low numbers of oocysts and genotyping C. parvum. Polymorphic alleles were differentiated by SYBR Green I and fluorescent probe melting curve analysis (MCA) on the basis of single-nucleotide polymorphisms (SNPs).

Advantages

Improved performance and efficiency, Genetic information obtained from the sample may permit nonhuman pathogens to be distinguished from human pathogens

\subsubsection{Multiplex Real-time PCR [84]}

Introduction of PCR based methods has been hindered by difficulties in DNA extraction from fecal samples. Moreover, the amplification and detection of DNA were prone to contamination as well as being timeconsuming and expensive. In recent years, however, the isolation of parasitic DNA from fecal samples has been improved and simplified. The introduction of real-time PCR with fluorescent detection probes can reduce the risk of contamination, labor time, and reagent costs through the possibility of combining assays for the detection of different targets into one assay. In all samples tested in which microscopy revealed the presence of $C$. parvum, specific amplification was detected. There was no difference in the performance of the amplification of the specific targets in the individual assays compared with the multiplex PCR, so the multiplex PCR could be used with equal confidence as the individual assays. PCR inhibition by fecal constituents is known to be a serious problem. However, there was no evidence of inhibition of the amplification in any of these samples with this DNA isolation method. Detection of parasite-specific DNA appears to be more sensitive than microscopy, as has been shown for $C$. parvum infections.

\section{Advantages}

It is a sensitive and specific method for the detection of $C$. parvum and offers the possibility of introducing DNA detection as a feasible technique in the routine diagnosis of intestinal parasitic infections.

\section{Limitations}

\section{Technical expertise reacquired}

2.4.2. Fluorescence In Situ Hybridization (FISH) using rRNA-targeted oligonucleotide probes [85]

This method relies on the hybridization of synthetic oligonucleotide probes to specific regions within the rRNA of the organism. While FISH has been applied for the detection of Cryptosporidium oocysts in water samples. This assay is based on species-specific probes for $C$. parvum and C. hominis.

Advantages

FISH can detect and identify pathogenic Cryptosporidium species in clinical, water, and environmental samples within a 3-h time frame. So, it is a reliable alternative to PCR and RFLP. It can distinguish between the two major species involved in human infections.

\subsubsection{Loop Mediated Isothermal Amplification (LAMP)}

Recently, parasitologists have started utilizing LAMP technology for detection of Cryptosporidium spp.[86] Loop-mediated isothermal amplification (LAMP) is a unique amplification method with extremely high specificity and sensitivity able to discriminate between a single nucleotide difference.[87] It is characterised by the use of six different primers specifically designed to recognise eight distinct regions on a target gene, with amplification only occurring if all primers bind and form a product. LAMP reactions are easy to set up, and results can readily be assessed. The sample of interest is mixed with primers, substrates, and a DNA polymerase capable of strand displacement in a microcentrifuge tube. During the reaction, large amounts of pyrophosphate ions are produced, leading to the formation of a white precipitate.[88] This turbidity is proportional with the amount of DNA synthesized therefore one can assess the reaction by real-time measurement of turbidity or more importantly, simply through the naked-eye. Recently, parasitologists have adapted the LAMP approach for the detection of several parasitic diseases including Cryptosporidium. Unlike a regular PCR reaction, LAMP is carried out at a constant temperature (usually in the range of $60-65^{\circ} \mathrm{C}$ ).

Advantages Higher yields, eliminates the need to buy a thermal cycler and shortens the reaction time by eliminating time lost during thermal changes.[89]

\section{Diagnosis of Extra Intestinal Cryptosporidiosis}

3.1. Biliary Cryptosporidiosis 
3.1.1. Ultrasonography- best initial diagnostic method. It will be suggestive in most cases by identifying biliary ductal wall thickening and/or gallbladder dilation or both.

3.1.2. Computerized tomography

3.1.3. endoscopic retrograde cholangiopancreatography (ERCP)

It is the most sensitive method

If biliary disease is highly suspected and the patient has normal ultrasonography, ERCP should be performed. However, ERCP is not recommended to work-up suspected asymptomatic AIDS cholangiopathy. The cholangiographic appearance of AIDS cholangiopathy is quite variable and has been described in different ways. Characteristically, the biliary tree appears irregular and distorted with focal dilation and narrowing in the intrahepatic and/or extrahepatic biliary tree. The most common cholangiographic pattern is papillary stenosis associated with intrahepatic sclerosing cholangitis, which occurs in approximately 50\%-60\% of patients. $[90,91,92]$

3.1.4. Percutaneous liver biopsy

Rarely helpful and thus plays no role in the diagnosis of AIDS-cholangiopathy.

3.1.5. Serum alkaline phosphatase- most commonly elevated liver biochemical test with mean values in most series of $700 \mathrm{IU} / \mathrm{L}-800 \mathrm{IU} / \mathrm{L}$.

3.1.6. Serum Aminotransferases

Mild increase in values. m.c. values range from 65 to 123IU/L.[90]

3.2. Pulmonary Cryptosporidiosis

Oocysts have been identified in sputum samples, tracheal aspirates, bronchoalveolar lavage fluid, brush biopsy specimens, and alveolar exudate obtained from lung biopsy.[6]

Due to presence of acid-fast oocysts in sputum sample and absence of any other pathogenic organism by microscopy or culture examination, Cryptosporidium was considered as an etiological agent for the pulmonary pathology in a study by Shrikhande et al.[93] Thus, pulmonary cryptosporidiosis should be considered as one of the differential diagnosis when an immunocompromised patient with respiratory symptoms is being investigated.

\section{RECENT ADVANCES IN DIAGNOSIS OF CRYPTOSPORIDIUM PARVUM}

Complete development of Cryptosporidium parvum in host cell-free culture medium (RPMI-1640) [94] Hijjawi et al [94] has shown for the first time that C. parvum can complete its entire life cycle without the need for host cells, with the presence of all developmental phases including merogony, gametogony, sporogony as well as recently described novel gamont-like stages that in RPMI 1640, are predominantly extracellular. Cheadle et al. (1999) also observed a microgamont-like stage in Cryptosporidium baileyi.[95]

Advantages: The production of large numbers of oocysts in vitro will facilitate all aspects of Cryptosporidium research including infectivity assessments and water treatment studies, Culture system is useful for drug evaluation studies where compounds can be tested against specific Cryptosporidium life cycle stages, potential for improving routine water and other environmental monitoring for Cryptosporidium, it may also allow the production of pure parasite material for future vaccine development, Cryptosporidium extracellular stages such as trophozoites, merozoites and gamont-like stages can be purified and surface molecules on these stages assessed as candidate antigens for the development of passive immunotherapy or vaccines

Limitations Labor intensive procedure, culturing is influenced by many factors such as host cell type and age, $\mathrm{pH}$, culturing conditions (temperature, $\mathrm{CO} 2$ ) and media supplements which can affect parasite cell invasion and development.

\section{FUTURE DIRECTIONS}

Significant advancements in our understanding of several aspects of Cryptosporidium biology are to a great extent dependent on development of suitable in vitro animal models. Laboratory animal models are needed to understand

- the pathophysiologic mechanisms by which the parasite or its metabolites damage the host mucosa

- The biology of C.parvum

- $\quad$ the pathophysiology and host immune response to extraintestinal infections of Cryptosporidium spp.

Mirza-Qavami et al [96] described a simple, economical, available and applicable animal model for C.parvum i.e. neonatal $\mathrm{BALB} / \mathrm{c}$ rats.

Advantages Pharmaceutical and prophylactic agents can be evaluated. This animal is easy to handle.

\section{CONCLUSION}

Many diagnostic tests are available for the diagnosis of Cryptosporidium parvum. Recent advances look promising in diagnosis of C.parvum infections. Till now, no single diagnostic test is fool proof and many of diagnostic tests recquire a set up and expertise. 


\section{BIBLIOGRAPHY}

[1]. Koneman E.W., Allen S.D., Janda W.M., Schreckenberger P.C., Winn Jr. W.C., Color atlas and textbook of diagnostic microbiology. (Philadelphia: Lippincott-Raven Publishers,2006).

[2]. Goodgame RW, Kimball K, and Ou CN, Intestinal hnction and injury in acquired immunodeficiency syndromerelated cryptosporidiosis, Gastroenterology, 108(4),1995, 1075- 82.

[3]. Xiao L, Morgan UM, Fayer R, Thompson RC, and Lal AA, Cryptosporidium systematics and implications for public health, Parasitol Today,16(7), 2000, 287-92.

[4]. Mosier DA, and Oberst RD, Cryptosporidiosis: a global challenge, Ann N Y Acad Sci,916, 2000,102-11.

[5]. O’Donoghue PJ, Cryptosporidium and cryptosporidiosis in man and animals. Int J Parasitol,25 (2), 1995,139-95.

[6]. Current WL, and Garcia LS, Cryptosporidiosis. Clin Microbiol Review,4(3),1991,325-58.

[7]. Hassan KM, Ali FE, and Bella MA, Cryptosporidiosis among children attending the maternity and paediatrics teaching hospital, Wad Medani, Central Region, Sudan. J Egypt Soc Parasitol, 21(1),1991, 213-8.

[8]. Janoff EN, Mead PS, Mead JR, Echeverria P, Bodhiditta L, Bhaibulay M, Sterling CR, and Taylor DN, Endemic Cryptosporidium and Giardia lamblia infections in a Thai orphanage, Am J Trop Med Hyg, 43(3), 1990,248-256.

[9]. Reinthaler FF, Mascher E, Sixl W, Enayat U, and Marth E, Cryptosporidiosis in children in Idukki distric in southern India, J Diarrhoel Dis Res, 7(3-4),1989, 89-91.

[10]. Moodley D, Jackson TE, Gathiram V, and van-den-Ende J, Cryptosporidium infections in children in Durban. Seasonal variation, age distribution and disease status, South Afr Med J, 79(6),1991, 295-7.

[11]. Jirapinyo P, Ruangsiri K, and Tesjaroen S, High prevalence of cryptosporidium in young children with prolonged diarrhea, Southeast Asian J Trop Med Public Health,24(4), 1993, 730-3.

[12]. Aye T, Moe K, Nyein MM, and Swe T, Cryptosporidiosis in Myanmar infants with acute diarrhea, Southeast Asian J Trop Med Public Health 25(4),1994,654-6.

[13]. Uppal B, and Natrajan R, Detection of cryptosporidium oocyst in acute diarrheal stools. Indian Paediatr,28(8),1991,917-20.

[14]. Mathan MM, Venkatesan S, George R, Mathew M, and Mathan VI, Cryptosporidium and diarrhoea in southern Indian children, Lancet,2(8465), 1985,1172-5.

[15]. Das P, Sengupta K, Dutta P, Bhattacharya MK, Pal SC, and Bhattacharya SK, Significance of cryptosporidium as an aetiologic agent of acute diahorrhoea in Calcutta: a hospital based study, J Trop Med Hyg,96(2),1993,124-7.

[16]. Sarawathi K, Pandit DV, Deodhar LP, and Bichile LS, Prevalence of cryptosporidia in patients with diarrhea in Bombay, Indian J Med Res, 87,1988, 221-4.

[17]. Das P, Pal S, Dutta D, and Bhattacharya MK, Cryptosporidium in Bengalee children with acute diarrhea, Trans $R$ Soc Trop Med Hyg,81(2), 1987,241.

[18]. Sethi S, Sehgal R, Malla N., and Mahajan RC, Cryptosporidiosis in a tertiary care hospital, National Med J India,12(5), 1999,207-9.

[19]. Garcia L.S., Intestinal protozoa (coccidian and microsporidia) and algae. In (ed.) Diagnostic Medical Parasitology, 4 (1752 N street NW, Washington DC 20036: ASM press, American Society for Microbiology, 2001) 60-105.

[20]. Arora DR, Arora B, Medical Parasitology (New Delhi, Bangalore, India: CBS Publishers and Distributers, 2005).

[21]. Chen X.M., Keithly J.S., Paya C.V., and LaRusso N.F., Cryptosporidiosis, N Engl J Med.,346 (22),2002,1723-31.

[22]. Chen X.M., and LaRusso N.F., Human intestinal and biliary cryptosporidiosis, World J. Gastroenterol.,5(5),1999,424-429.

[23]. Albuquerque Y.M., Silva M.C., Lima A.L., and Magalhães V., Pulmonary cryptosporidiosis in AIDS patients, an underdiagnosed disease, J Bras Pneumol.,38(4), 2012,530-532.

[24]. Parija S.C., Textbook of Medical Parasitology: Protozoology \& Helminthology Text and Colour atlas (New Delhi, Chennai,India: All India Publishers \& Distributers, 2007)

[25]. Anderson, B. C., Cryptosporidiosis. Lab. Med., 14, 1983,55-56.

[26]. Garcia, L.S., Bruckner D.A., Brewer T.C., and Shimizu R.Y., Techniques for the recovery and identification of Cryptosporidium oocysts from stool specimens, J. Clin. Microbiol.,18(1),1983,185-90.

[27]. Casemore D.P., Armstrong M., and Sands R.L., Laboratory diagnosis of cryptosporidiosis, J. Clin. Pathol.,38(12),1985,1337-41.

[28]. Zierdt W.S., Concentration and identification of Cryptosporidium sp. by use of a parasite concentrator, J. Clin. Microbiol.,20(5), 1984,860-1.

[29]. McNabb S.J., Hensel D.M., Welch D.F., Heibel H., McKee G.L., and Istre G.R., Comparison of sedimentation and flotation techniques for identification of Cryptosporidium sp. oocysts in a large outbreak of human diarrhea, $J$. Clin. Microbiol., 22(4) ,1985,587-9.

[30]. Delf'in, M., Sanjurjo E., Findlay C.M., and Gordeeva L.M., Cryptosporidium sp. in children with diarrhea in Cuba, Med. Parazitol(Mosk.),4,1989,36-9.

[31]. Parmeshwarappa K.D., Chandrakanth C., and Sunil B, The Prevalence of Intestinal Parasitic Infestations and Evaluation of Different Concentration Techniques of the stool Examination., Journal of Clinical and Diagnostic Research,2012.Availableat: http://www.jcdr.net/articles/PDF/2392/4662_E(C)_F(P)_PF1(V)_PFA(P)_OLF(P).pdf

[32]. Current W.L., and Reese N.C, A comparison of endogenous development of three isolates of Cryptosporidium in suckling mice. J. Protozool.,33(1),1986,98-108.

[33]. Goebel, E., and U. Brandler., Ultrastructure of microgametogenesis, microgametes, and gametogony of Cryptosporidium sp. in the small intestine of mice, Protistologica, 18,1982,331-334.

[34]. Potters I., and Van Esbroeck M., Negative Staining Technique of Heine for the Detection of Cryptosporidium spp.: A Fast and Simple Screening Technique, The Open Parasitology Journal.,4,2010,1-4. 
[35]. Ma P., Laboratory diagnosis of coccidiosis, in L. Leive and D. Schlessinger (ed.), Microbiology (Washington, D.C., American Society for Microbiology, 1984) 224-231.

[36]. Ma P., and Soave R., Three-step stool examination for cryptosporidiosis in 10 homosexual men with protracted watery diarrhea, J. Infect. Dis., 147(5),1983,824-8.

[37]. Elsser K.A., Moricz M., and Proctor E.M., Cryptosporidium infections: a laboratory survey ,CMAJ., 135(3), 1986,211-3.

[38]. Barua P., Hazarika N.K., Barua N., Rasul E., and Laskar N., Microscopy for Cryptosporidiosis Screening in Remote Areas,IJMM.,26(2),2007,203-4.

[39]. Casemore DP, ACP Broadsheet 128: June 1991. Laboratory methods for diagnosing cryptosporidiosis, J Clin Pathol,44(6), 1991, 445-51.

[40]. Chartier C, Mallereau-Pellet MP, Mancassola R, and Nussbaum D., Détection des oocystes de Cryptosporidium dans les fèces de caprins : comparaison entre un test d'agglutination au latex et trios autres techniques conventionnelles. Vet Res,33(2),2002, 169-77.

[41]. Paul S, Chandra D, Tewari AK, Banerjee PS, Ray DD, Boral R, and Rao JR, Comparative evaluation and economic assessment of coprological diagnostic methods and PCR for detection of Cryptosporidium spp. in bovines, Vet Parasitol., 164(2-4), 2009, 291-5.

[42]. Baxby D., Blundell N., and Hart C.A., the development and performance of a simple, sensitive method for detection of Cryptosporidium oocysts, J. Hyg.(Lond.), Camb.,93(2),1984,317-23.

[43]. Pohjola, S., Negative staining method with nigrosin for the detection of cryptosporidial oocysts-a comparative study, Res. Vet. Sci.,36(2),1984,217-9.

[44]. Current W. L., Human cryptosporidiosis, N. Engl. J.Med.,309,1983,1326-1327.

[45]. Heine J.,Eine einfache Nachweismethode für Kryptosporidienim Kot,Zentrabl Veterinarmed B.,29(4), 1982, $324-7$.

[46]. Elliot A., Morgan U.M. and Thompson R.C., Improved staining method for detecting Cryptosporidium oocysts in stools using malachite green, J. Gen. Appl. Microbiol.,45(3),1999,139-142.

[47]. Pohjola, S., Jokipii L., and Jokipii A.M., Dimethylsulphoxide-Ziehl-Neelsen technique for detection of cryptosporidial oocysts, Vet. Rec.,116(16),1985,442-3.

[48]. Alpert G., Bell L.M., Kirkpatrick C.E., Budnick L.D., Campos J.M., Friedman H.M., and Plotkin S.A., Outbreak of cryptosporidiosis in a day care center, Pediatrics 77(2),1986,152-7.

[49]. Bronsdon M.A., Rapid dimethyl sulfoxide-modified acid-fast stain of Cryptosporidium oocysts in stool specimens, J. Clin. Microbiol., 19(6), 1984,952-3.

[50]. Nichols G., and Thom. B.T., Screening for Cryptosporidium in stools, Lancet 1(8379),1984,734-5.

[51]. Payne P., Lancaster L.A., Heinzman M., and Mc-Cutchan J.A., Identification of Cryptosporidium in patients with acquired immunodeficiency syndrome, N. Engl. J. Med.,309(10),1983,613-614.

[52]. Khurana S., Sharma P., Sharma A., and Malla N, Evaluation of Ziehl-Neelsen staining, auramine phenol staining, antigen detection enzyme linked immunosorbent assay and polymerase chain reaction, for the diagnosis of intestinal cryptosporidiosis, Trop.Parasitol.,2(1),2012,20-23.

[53]. Corbett-Feeney G., Cryptosporidium among children with acute diarrhea in the west of Ireland, $J$. Infect., 14(1), 1987,79-84.

[54]. Casemore D.P.,Armstrong M and Jackson B.,Screening for Cryptosporidium in stools, Lancet, 1(8379),1984,734-5.

[55]. Garcia L.S., BrewerT.C., and Bruckner D.A., Fluorescent detection of Cryptosporidium oocysts in human fecal specimens by using monoclonal antibodies, J. Clin. Microbiol.,1987,25(1),119-21.

[56]. Alles A.J., Waldron M.A., Sierra L.S., and Mattia A.R., Prospective Comparison of Direct Immunofluorescence and Conventional Staining Methods for Detection of Giardia and Cryptosporidium spp. in Human Fecal Specimens, J.Clin Microbiol.,33(6),1995,1632-4.

[57]. Kamal K.A., EI-Diban N.A., and Hassanin F.S., Evaluation of Immunoflourescent Antibody (IFA) Kit for the Detection of Cryptosporidium parvum Oocysts and Giardia lamblia Cysts in Stool Specimens, Parasitologists United J.,1(2), 2008,145-7.

[58]. Campbell P.N., and Current W.L., Demonstration of serum antibodies to Cryptosporidium sp. in normal and immunodeficient humans with confirmed infections, J. Clin. Microbiol.,18(1),1983,165-169.

[59]. Casemore, D. P., The antibody response to Cryptosporidium: development of a serological test and its use in a study of immunologically normal persons, J. Infect., 14(2),1987,125-34.

[60]. Ungar B. L., Soave R., Fayer R., and Nash T.E., Enzyme immunoassay detection of immunoglobulin M and G antibodies to Cryptosporidium in immunocompetent and immunocompromised persons, J. Infect. Dis., 153(3), 1986,570-8.

[61]. Ungar, B. L., Gilman R.H., Lanata C.F., and Perez-Schael I., Seroepidemiology of Cryptosporidium infection in two Latin American populations, J. Infect. Dis.,157(3),1988,551-6.

[62]. Weitzel T., Dittrich S., Mo“hl I., Adusu E. and Jelinek T, Evaluation of seven commercial antigen detection tests for Giardia and Cryptosporidium in stool samples, Clin Microbiol Infect., 12(7), 2006, 656-9.

[63]. Kehl K.S., Cicirello H., and Havens P.L., Comparison of four different Methods for Detection of Cryptosporidium species, J. Clin. Microbiol.,33(2),1995,416-8.

[64]. Ungar B.L., Enzyme-Linked Immunoassay for Detection of Cryptosporidium Antigens in Fecal specimens, J. Clin. Microbiol.,28(11), 1990, 2491-5.

[65]. Chapman P.A., Rush B.A., and McLauchlin J., An enzyme immunoassay for detecting Cryptosporidium in faecal and environmental samples, J. Med. Microbiol.,32(4),1990,233-7.

[66]. Arya S.C., Cryptosporidium Antigen Detection in Human Feces by Reverse Passive Hemagglutination Assay, J. Clin. Microbiol.,33(6),1995,1684-5. 
[67]. Farrington M., Winters S., Walker C., Miller R., and Rubenstein D., Cryptosporidium antigen detection in human feces by reverse passive hemagglutination assay, J. Clin. Microbiol.,32(11),1994,2755-9.

[68]. Diagnostic Procedures for Stool Specimens; Detection of Parasite antigens. [Internet].2012 [Updated 2009 July 20, cited 2012 October 02]. Available from: http://dpd.cdc.gov/dpdx/HTML/DiagnosticProcedures.htm

[69]. Arrowood M.J., Hurd M.R., and Mead J.R., A new method for evaluating experimental cryptosporidial parasite loads using immunofluorescent flow cytometry, J. Parasitol. ,81(3), 1995,404-9.

[70]. Valdez LM., Dang H., Okhuysen P.C., and Chappell C.L., Flow Cytometric Detection of Cryptosporidium Oocysts in Human Stool Samples, J. Clin. Microbiol.,35(8),1997,2013-7.

[71]. http://www.luminexcorp.com/

[72]. Ndao M., Diagnosis of Parasitic Diseases: Old and New Approaches, Interdisciplinary Perspectives on Infectious Diseases,2009, 2009 Article ID 278246, 15 pages. doi:10.1155/2009/278246

[73]. Fricker C.R., and Crabb J.H., Water-borne cryptosporidiosis: detection methods and treatment options, $A d v$. Parasitol.,40,1998,241-78.

[74]. Widmer G.,Genetic heterogeneity and PCR detection of Cryptosporidium parvum, Adv.Parasitol.,40,1998,223-39.

[75]. Morgan U.M., and Thompson R.C., PCR detection of Cryptosporidium: the way forward?, Parasitol. Today.,14(6), 1998,241-5.

[76]. Clark D.P., New Insights into Human Cryptosporidiosis, Clin.Microbiol.Rev., 12(4),1999,554-63.

[77]. Morgan U.M., Pallant L., Dwyer B.W., Forbes D.A., Rich G. and Thompson R. C. , Comparison of PCR and Microscopy for Detection of Cryptosporidium parvum in Human Fecal Specimens: Clinical Trial, J.Clin. Microbiol.,36(4),1998,995-8.

[78]. Amar C.F., Dear P.H., and McLauchlin J., Detection and identification by real time PCR/RFLP analyses of Cryptosporidium species from human faeces, Lett. Appl. Microbiol.,38(3),2004,217-222.

[79]. Limor J.R., Lal A.A., and Xiao L., Detection and differentiation of Cryptosporidium parasites that are pathogenic for humans by real-time PCR, J. Clin. Microbiol.,40(7),2002,2335-8.

[80]. Tanriverdi S., Arslan M.O., Akiyoshi D.E., Tzipori S., and Widmer G., Identification of genotypically mixed Cryptosporidium parvum populations in humans and calves, Mol. Biochem. Parasitol.,130(1),2003,13-22.

[81]. Higgins J.A., Fayer R., and Trout J.M, Real-time PCR for the detection of Cryptosporidium parvum, J. Microbiol. Methods.,47,2001,323-337.

[82]. Hadfield S.J., Robinson G., Elwin K., and Chalmers R.M., Detection and Differentiation of Cryptosporidium spp. in Human Clinical Samples by Use of Real-Time PCR, J. Clin. Microbiol.,49(3),2011,918-24.

[83]. Tanriverdi S., Tanyeli A., Baslamisli F., Köksal F., Kilinç Y., Feng X., Batzer G., Tzipori S., and Widmer G., Detection and Genotyping of Oocysts of Cryptosporidium parvum by Real-Time PCR and Melting Curve Analysis, J. Clin. Microbiol., 40(9),2002,3237-44.

[84]. Verweij JJ, Blange RA, Templeton K, Schinkel J, Brienen EAT, van Rooyen MAA, van Leishout L, Polerman AM, Simulatnous detection ofEntamoeba histolytica, Giardia lamblia, and Cryptosporidium parvum in fecal samples using multiplex real-time PCR, J Clin Microbiol.,42(3),2004, 1220-1223.

[85]. Alagappan A., Bergquist P.L., and Ferrari B.C., Development of a Two-Color Fluorescence In Situ Hybridization technique for species level identification of Human- Infectious Cryptosporidium spp., Appl. Environ. Microbiol.,75(18),2009,5996-8.

[86]. Bakheit MA, Torra D, Palomino LA, Thekisoe OM, Mbati PA, Ongerth J, and Karanis P., Sensitive and specific detection of Cryptosporidium species in PCR-negative samples by loop-mediated isothermal DNA amplification and confirmation of generated LAMP products by sequencing, Vet Parasitol.,158(1-2),2008,11-22.

[87]. Parida M, Sannarangaiah S, Dash PK, Rao P.V., Morita K., Loop mediated isothermal amplification (LAMP): a new generation of innovative gene amplification technique; perspectives in clinical diagnosis of infectious diseases, Rev Med Virol.,18(6),2008,407-21.

[88]. Mori Y., Nagamine K.,Tomita N., and Notomi T., Detection of loop-mediated isothermal amplification reaction by turbidity derived from magnesium pyrophosphate formation, Biochem Biophys Res Commun,289(1),2001,150-4.

[89]. Han ET, Watanabe R, Sattabongkot J, Khuntirat B, Sirichaisinthop J, Iriko H, Jin L, Takeo S, Tsuboi T., Detection of four Plasmodium species by genus- and species-specific loop-mediated isothermal amplification for clinical diagnosis, J Clin Microbiol,45(8),2007,2521-8.

[90]. Wilcox CM, Mönkemüller KE., Hepatobiliary diseases in patients with AIDS: focus on AIDS cholangiopathy and gallbladder disease, Dig Dis., 16(4),1998, 205-13.

[91]. Farman J, Brunetti J, Baer JW, Freiman H, Comer GM, Scholz FJ, Koehler RE, Laffey K, Green P, and Clemett AR, AIDS related cholangiopancreatographic changes, Abdom Imaging, 19(5), 1994,417-22.

[92]. Ducreux M, Buffet C, Lamy P, Beaugerie L, Fritsch J, Choury A, Liguory C, Longuet P, Gendre JP and Vachon F,et al., Diagnosis and prognosis of AIDS-related cholangitis. AIDS,9(8),1995,875-80.

[93]. Shrikhande S.N., Chande C.A., Shegokar V.R. and Powar R.M., Pulmonary cryptosporidiosis in HIV negative, immunocompromised host, Indian J. Pathol. Microbiol.,52(2),2009,267-68.

[94]. Hijjawi N.S., Meloni B.P., Ng'anzo M., Ryan U.M., Olson M.E, Cox P.T., Monis P.T., and Thompson R.C., Complete development of Cryptosporidium parvum in host cell-free culture, Int J Parasitol,34(7),2004,769-77.

[95]. Cheadle, M.A., Toivio-Kinnucan, M., and Blagburn, BL, The ultrastructure of gametogenesis of Cryptosporidium baileyi (Eimeriorina; Cryptosporidiidae) in the respiratory tract of Broiler chickens (Gallus domesticus), $J$. Parasitol.,85(4),1999,609-15.

[96]. Mirza-Qavami S.M, and Sadraei J., An examination of Cryptosporidium parvum infection in neonate BALB/c mice and rats, JJM.,4(3),2011,185-190. 